Session 1663

\title{
Designing a Global Ethic for Engineers
}

\author{
Joel L. Cuello, Ph.D. \\ Department of Agricultural and Biosystems Engineering, The University of Arizona \\ 507 Shantz Building, Tucson, AZ 85721 \\ Tel (520) 621-7757, Fax (520) 621-3963, Email jcuello@ag.arizona.edu
}

It was Bill Ford, Chairman and Chief Executive Officer of the Ford Motors Company, who made the remark that "A good company delivers excellent products and services, while a great one delivers excellent products and services and strives to make the world a better place." This statement remains strikingly true when adapted to engineering professional organizations, that is, "A good engineering professional organization delivers excellent products and services, while a great one delivers excellent products and services and strives to make the world a better place." But have the various national and regional engineering professional organizations around the globe striven properly in the last century to make the world a better place?

The answer is both yes and no. It is yes as attested by the illustrious list of greatest engineering achievements of the $20^{\text {th }}$ century ${ }^{1}$ published in 2000 by the National Academy of Engineering, which included: electrification; the automobile; the airplane; water supply and distribution; electronics; radio and television; agricultural mechanization; computers; the telephone; air conditioning and refrigeration; highways; spacecraft; the internet; imaging; household appliances; health technologies; petroleum and petrochemical technologies; laser and fiber optics; nuclear technologies; and high-performance materials. But the answer is also no since, despite or sometimes even because of the foregoing technical accomplishments, millions of people today are living in poverty and the degradation of the environment remains largely unabated. Thus, at the dawn of the $21^{\text {st }}$ century, the engineering professions face up to the burden and the challenges of their significant and unfinished work.

A New Global Ethic for Engineers: The Need

During the last century, the Code of Ethics of Engineers ${ }^{2}$ was developed, founded on its first fundamental principle of "upholding and advancing the integrity, honor and dignity of the engineering profession by using their knowledge and skill for the enhancement of human welfare." ${ }^{2}$ Indeed, guided by such ethical mission, engineers designed products and processes for the betterment of societies and nations. It certainly is not an exaggeration to state that engineering has been one of the most effective and powerful tools of development in the last 100 years. The experiences of the last century and the recent trend toward market globalization, however, have 
revealed a subtler picture of how the engineers' products and processes actually affect certain societies or nations. The inevitable observation is that introducing new engineering technologies into a social system stacked in favor of the rich and against the poor ${ }^{3}$ - without addressing the social questions of access to the technology's benefits ${ }^{3}$ - will, over time, lead to an even greater concentration of rewards from engineering technologies. As a corollary, the application of engineering technologies -- given a social framework that heavily limits access to such technologies in favor of the rich -- can very well contribute to more, not less, global poverty and hunger. This points to the defect in the current model of operation of engineers, labeled here as the Partial or Narrow Approach (Figure 1), which has its almost exclusive focus on technical progress, and presumes that the engineers' products and services will always have "good" effects on their customers (individuals, organizations or nations) when released in the open market.

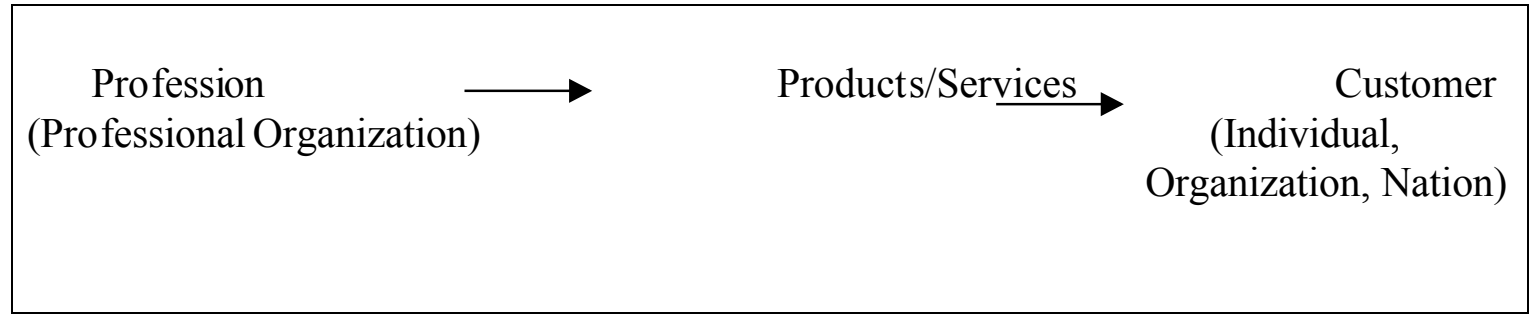

FIGURE 1. The Partial or Narrow Approach, with narrow focus on achieving technical progress.

With this model, new technologies are continually churned out, but how these technologies actually affect the customers who live within real-world economic, social and political arrangements is conveniently overlooked. And since the market behaves independently of the social values of its participants, ${ }^{4}$ and is motivated by profit, ${ }^{4}$ only the privileged ones with purchasing power are able to avail of the benefits of the technology products that are released through the open market, ${ }^{3}$ inexorably widening the pre-existing inequalities within nations and between nations. ${ }^{5}$ This is clearly in violation of the first fundamental principle of the Code of Ethics of Engineers. ${ }^{2}$

There is also the matter of the environment. The industrial revolution and the industrialization of agriculture, among other major engineering breakthroughs in the last century, have led to the rapid degradation of the environment. It is well documented that the concentrations of greenhouse gases in the atmosphere have rapidly escalated in the last century, that the destruction of the world's rainforests remains unmitigated, and that industrialized agriculture has helped brought about, if inadvertently, the long-term degradation of the soil. ${ }^{3}$ As reported by the Institute for Food and Development Policy, for instance, roughly $70 \%$ of the 5.2 billion hectares of dry lands used for agriculture around the world are in danger of being turned to deserts. ${ }^{3}$ It is noteworthy that more than one billion people in 135 countries depend on this land. ${ }^{3}$ The foregoing unintended but destructive effects of engineering technologies on the global environment are also clearly in violation of the first fundamental principle of the Code of Ethics of Engineers. ${ }^{2}$

The Code of Ethics of Engineers ${ }^{2}$ as originally designed remains pertinent as a guide to the individual engineer. In view, however, of the fact that the reach and influence of the products and

"Proceedings of the 2003 American Society for Engineering Education Annual Conference \& Exposition Copyright (C) 2003, American Society for Engineering Education" 
processes designed by engineers are no longer merely local, but altogether global - bought, distributed and sold in a globalized market with potential or actual adverse effects on certain nations and the environment -- there arises a pressing need to develop a new global ethic for engineers that will both galvanize and inform their collective social voice and action.

\section{A New Global Ethic for Engineers: Theory}

With what is known now from the last century, it is no longer sufficient for the engineering professional organizations to assume that their technology products will automatically accomplish their intended beneficial ends for their customers. Indeed, the use of these technology products could very well result in the opposite of what is intended to happen - harming, instead of benefiting, the customers. It thus is imperative for the engineering professional organizations to design for engineers an ethic that is wider, more expansive and global in scope.

Following are the three cardinal principles of this new global ethic for engineers:

1. Engineers have a trans-border responsibility, across national, racial, cultural, social and economic boundaries. ${ }^{5}$ The principal responsibility of engineers is the enhancement of human welfare -- promoting not the welfare of some, but promoting the welfare of all human beings. ${ }^{2,5,6}$ Engineers have in view the safety, material improvement, etc., of all human beings on the planet;

2. Engineers have the responsibility of designing products and technologies with a view to sustainable development, i.e., "development that meets the needs of the present without compromising the ability of future generations to meet their own needs." $", 7$ The promotion of human welfare encompasses the conservation of the environment, since human welfare and the long-term integrity of the environment are inextricably intertwined. Engineers must integrate development and conservation, promote the stewardship of the global environment and uphold the commonwealth of life; $;, 7$ and,

3. Engineers, as a member of the global civil society, ${ }^{5}$ have the responsibility of helping ensure the primacy of human welfare over politics and the global economy, ${ }^{5,7}$ being vigilant in ensuring that engineering technologies do not end up as mere instruments which further widen the gap between the haves and the have-nots or which further heighten the wall of separation between the outsiders and the insiders in a globalized economy. ${ }^{8}$

\section{A New Global Ethic for Engineers: Practice}

Adopting the new global ethic for engineers means that engineers collectively will have to make their hands busy with something that they are customarily averse to handling - policy. Engineers need to realize, however, that if they are to pay more than lip service to the first fundamental principle of their Code of Ethics, ${ }^{2}$ becoming involved in shaping policy is not a choice, but a compelling obligation. Helping shape policy is the one critical step that is indispensable in ensuring that the intended beneficial effects of engineering technologies to all of humanity remain just that - beneficial. 
It is high time and only just that the various engineering professional organizations around the globe jettison the Partial or Narrow Approach and adopt a new Comprehensive Approach as their new model of operation. The Comprehensive Approach (Figure 2), instead of being narrowly and exclusively focused on technical progress, aims to achieve technical progress in the deliberate service of universal human welfare and sustainable development. In essence, the Comprehensive Approach demands two principal requirements from the engineering professional organizations: (1) for them to become keenly aware of the long-term effects of their technology products and services on their customers (individuals, organizations, nations) for prompt corrective measures when necessary; and, (2) for them to have a say and influence on government or economic policies that dictate how the engineers' products and services are made available to and are used by individuals, organizations and nations to ensure their intended beneficial effects for all of humanity.

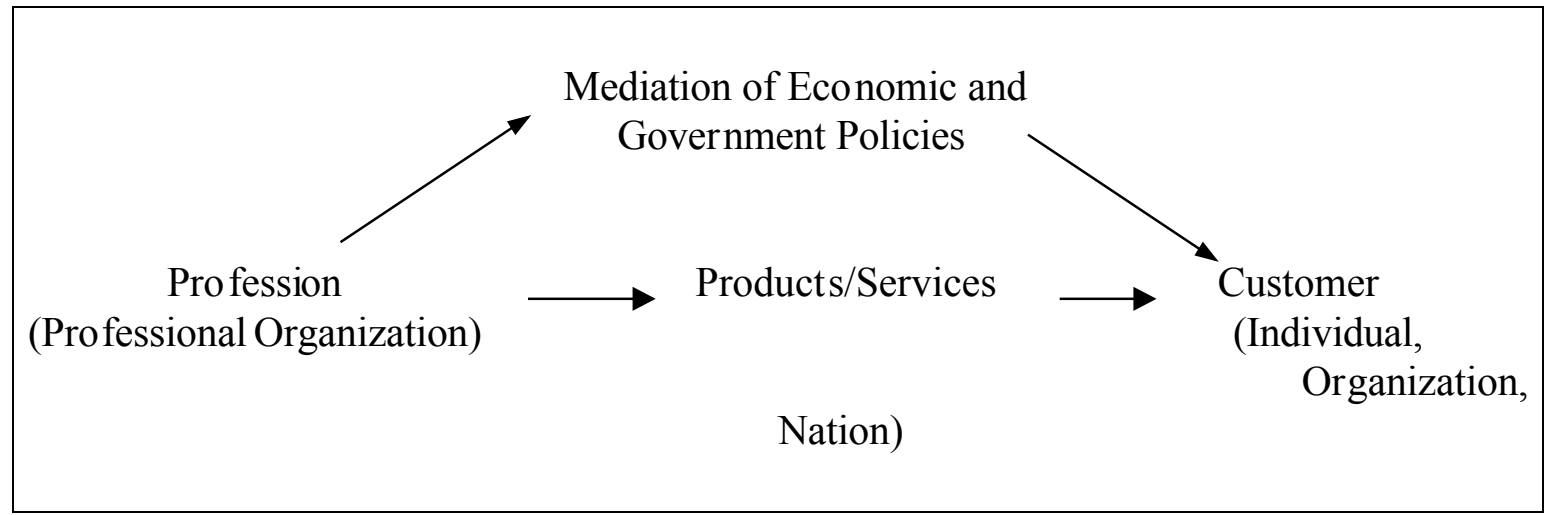

FIGURE 2. The Comprehensive Approach, with focus on achieving technical progress in the deliberate service of universal human welfare and sustainable development.

The Comprehensive Approach has the following four main thrusts in the service of universal human welfare and sustainable development:

1. Monitor and document actual and unforeseen effects of engineering technology products and packages over time in developed and developing countries;

2. Recommend a comprehensive "best-usage" scenario for a specific engineering technology product or package, addressing specific needs in developed or developing countries. A comprehensive "best-usage" scenario incorporates economic, social, political and cultural factors;

3. Promote the development of specific technology products within the context of a highlevel development objective. An example of a specific high-level development objective is how to make life in the rural areas more attractive to help stem urban migration in developing countries. Candidate technologies may include those applicable toward lowcost housing, water supply and irrigation, etc.; and, 
4. Submit position statements, technical briefings, letters of regulatory comments, and testimonies as needed to pertinent national and international governing bodies and grant agencies to help ensure the intended beneficial effects of engineering technologies to all of humanity.

Working out the Comprehensive Approach must be tackled in the level of the professional organizations. This is not meant to be tackled in the level of the individual engineers. The individual engineer cannot and should not be allowed to agonize over how the use of the technology products or package that he or she is designing could exacerbate inequities through the open market. Such tendency of the market can only be addressed in the policy level, which must be mediated in the professional-organization level, a critical component of civil society. This is the level at which the social responsibility of the profession is appropriately carried out, and where the collective will and conscience of the profession should be duly expressed and enforced.

The World Federation of Engineering Organizations (WFEO) is well positioned to carry out the four main thrusts of the Comprehensive Approach in behalf of all the engineering professional organizations around the globe. The WFEO could orchestrate the policy efforts of all its member engineering professional societies and present resolutions in behalf of the whole engineering profession especially in the level of nations and the international arena. It would be expedient for the WFEO to establish its own policy-making House of Delegates, which would consist of representatives from member engineering organizations, for the purpose of coordinating, developing and implementing the WFEO's global policies. Also, this would truly confer substance to the WFEO's major objects, which include: "to encourage the application of technical progress to economic and social advancement; to advance engineering as a profession in the interest of all people; and to foster peace throughout the world."

Each of the engineering professions, at the same time, could act on its own and in concert with the WFEO. For instance, in the case of Agricultural Engineering, the American Society of Agricultural Engineers (ASAE) could charge its Committee for Issues Management and Social Action to carry out the four main thrusts of the Comprehensive Approach. Similarly, each of the agricultural-engineering professional organizations around the globe could establish and put to work a similar committee if one is not in existence yet. Then, the International Commission of Agricultural Engineering (CIGR) could serve as overall global facilitator and mediator, orchestrating the policy efforts of the various agricultural-engineering professional organizations, especially pertaining to the level of nations and in the international arena. It would also be expedient for CIGR to establish its own policy-making House of Delegates, which would consist of representatives from the CIGR member organizations, for the purpose of coordinating, developing and implementing global policies in behalf of the profession. In carrying out the major thrusts of the Comprehensive Approach, CIGR should be proactive to engage in continual dialogue pertinent national governments and such development institutions as the Asian Development Bank, the World Bank, the Food and Agricultural Organization of the United Nations, etc.

This enterprise will for sure necessitate that the engineering professions seek the cooperation of experts from other fields, such as economists, sociologists, development policy-makers, etc.

"Proceedings of the 2003 American Society for Engineering Education Annual Conference \& Exposition Copyright $\mathbb{0}$ 2003, American Society for Engineering Education” 
What an excellent way for the engineering professions to demonstrate to their members - both professional and pre-professional - that their contributions do not exist in a vacuum, but become part of larger complex solutions whose success depends on their cooperating and working together with other experts. ${ }^{6}$

It is imperative that engineering education in the $21^{\text {st }}$ century includes the inculcation among engineering students that it is no longer sufficient for them to assume simply that their technology products, when released in the open market, will automatically accomplish their intended beneficial ends for their customers (individuals, organizations or nations). Indeed, the use of their technology products in places where social questions of access to the technology's benefits remain un-addressed could very well result in the opposite of what is intended to happen harming, instead of benefiting, their customers. Thus, today's engineers need to be educated, not only with the Code of Ethics of Engineers ${ }^{2}$ that serves as a guide to the individual engineer, but also with a new Global Ethic for Engineers that is wider, more expansive in scope, and which is best carried out collectively through their professional engineering organizations.

On hindsight, perhaps it was neither possible nor advisable for the engineering professional organizations to work out the Comprehensive Approach during the last century since: (1) the various engineering professions were going through their maturation period; (2) the complex dynamics between technical progress and development were just starting to become manifest; and (3) the necessary interdependence among ostensibly discrete and unrelated disciplines in formulating comprehensive solutions to development problems was only starting to become evident. Today at the beginning of $21^{\text {st }}$ century, however, a much better understanding of the complex relationships between technical progress and development has emerged, with the grounded realization that a narrow focus on technical progress alone does not necessarily or directly translate to development. What is more, the engineering professions have achieved a robust maturity that they are now ready to cooperate with other disciplines in working out meaningful and effective solutions. The various engineering professional organizations around the globe, as well as the World Federation of Engineering Organizations, are very well positioned today to choose and practice the Comprehensive Approach. It is this that will determine by the end of another hundred years whether the various engineering professions will have become great engineering professions -- or merely good ones.

Bibliographic Information

1. National Academy of Engineering. 2000. Greatest Engineering Achievements of the $20^{\text {th }}$ Century. www.greatachievements.org/greatachievements/indexp.html.

2. Accreditation Board for Engineering and Technology. Code of Ethics of Engineers. http://www.che.boun.edu.tr/ethics.html.

3. Lappe, F.M, J. Collins, P. Rosset and L. Esparza. 1998. World Hunger: Twelve Myths. $2^{\text {nd }}$ ed. New York, NY: Grove Press.

4. Soros, G. 2000. Open Society: Reforming Global Capitalism. New York, NY: Public Affairs.

5. Brown, P. 1999. Ethics, Economics and International Relations. Edinburgh: Edinburgh University Press.

"Proceedings of the 2003 American Society for Engineering Education Annual Conference \& Exposition Copyright (C) 2003, American Society for Engineering Education” 
6. Cuello, J.L. 1999. The Cultural Values of Engineering. The Bent. XC (1):18-20.

7. Kung, H. 1998. A Global Ethic for Global Politics and Economics. New York, NY: Oxford University Press.

8. Annan, Kofi. 2002. World Inclusivity: The Walls Have to Come Down. International Herald Tribune. October 4, 2002.

\section{Biographical Information}

Joel L. Cuello is an Associate Professor in the Department of Agricultural and Biosystems Engineering at The University of Arizona, where he has taught since 1995. He obtained his B.S. in Agricultural Engineering from The University of the Philippines at Los Banos in 1984. His three graduate degrees were all obtained from Penn State, including his M.S. (1990) and Ph.D. (1994) in Agricultural and Biological Engineering and a second M.S. in Plant Physiology (1999). Dr. Cuello spent one year in 1994 as a National Research Council Research Associate at NASA John F. Kennedy Space Center in Cape Canaveral, Florida. He is active in both the Institute of Biological Engineering (IBE) and ASAE, The Society for Engineering in Agricultural, Food and Biological Systems. He can be reached at 507 Shantz Building, The University of Arizona, Tucson, AZ 85721; TEL 520-621-7757; FAX 520-621-3963; EMAIL jcuello@ag.arizona.edu. 